\title{
Dreaming in crisis
}

\author{
Maddie Neufeld ${ }^{1}$
}

Accepted: 4 November 2020 / Published online: 5 January 2021

(C) UNESCO IBE 2021

\begin{abstract}
This article explores how socio-political crises that implicate teachers and students play out in dreams about the psychical and material realities of schooling. Teacher dreaming during crisis reveals the impossibility of the dream of education - a fantasy of control, protection, and transformation of students. The author analyzes her own teacher fantasies of protecting and transforming students during crisis as they are unfurled in her dreams to be just that, fantasies. The crises of violence and remoteness, as engendered by antisemitism, school fighting, and Covid-19, expose the fissures of this fantasy through the transferential time and ties of teaching. Ultimately, the conflicts that ensue from dreaming during crisis generate possibilities of learning through crisis.
\end{abstract}

Keywords Antisemitism $\cdot$ Covid-19 $\cdot$ Crisis $\cdot$ Dreams $\cdot$ Teachers

The visionary dream of education as "the great equalizer" (Horace Mann, as cited in Bowles and Gintis 2011, p. 26) is an impossibility, as we see the perpetuation of racism, classism, sexism, and ableism in schooling, despite efforts to close the spectral "achievement gap". The dream of education, therefore, is exposed as an impossibility; its fantasy of progress is revealed as an elusive wish to control, protect, and transform students.

Dreaming offers an avenue for the unconscious to speak, unraveling fantasies, fears, and desires through fragmented nighttime scenes. Freud and Brill (1913, p. 136) explained dreaming as "the (disguised) fulfillment of a (suppressed, repressed) wish", while contemporary psychoanalysis has suggested that dreams may also reveal the dreamer's concerns without disguise (Blechner 2018). Alternatively, visionary dreaming encourages us to imagine a new world, one in which the broken is not so broken-a world in which we are whole, a fantasy in and of itself. What, then, does it mean to dream in crisis?

Maddie Neufeld

mn2710@tc.columbia.edu

1 Teachers College, Columbia University, New York, NY 10027, USA 
Education is itself a dream whose underside reveals "the desire for omnipotence, transcendence, innocence, domination" (Britzman 1998, p. 10). If schools and teachers are projected as a panacea for social ill, what happens when they are ailing? How does the dream of education as a cure collapse into actual teacher dreams about the impossibility of education (Felman 1982; Taubman 2012)? In this article, I will explore how this underside plays out through transference in dreams about teaching in and during crisis. I will examine several of my own dreams, as documented in a dream journal, connected to two crises. The first is the rise in antisemitic hate crimes that coincided with an increase in fighting between students at the school at which I was working. The second is the Covid-19 pandemic, which created a crisis of remote learning. While these two crises are different in theme and scope, both activate transferential fantasies and fears of the teacher as "the subject presumed to know" (Felman 1982).

I heed Britzman and Pitt's (1996) call that "learning at its most flawed moment might allow for a different kind of insight into learning itself" (p. 119). How does the teacher work through the collapse of "the dream of education" (Britzman 1998, p. 10) as and during crisis? How can teachers be visionary when education is an impossibility (always) and even more literally with the threat of violence, illness, and isolation? In this article, as I analyze my own teacher dreams of protecting and transforming students during crisis the dream of education is put into crisis. This self-analysis demonstrates that when we tend to the experiences of learning in crisis, we learn from it. As I interpret my own dreaming in crisis, I peel back the façade of education as a dream so as to expose renewed possibilities for relationality in learning.

Schooling and students become sites onto which the teacher, as a dreaming subject, projects their fears and desires. This projection is a way to protect the fantasy of education as a possible means of creating control, order, and coherence, but it simultaneously exposes the fissures of that fantasy-its impossibility. The transferential ties of teaching reveal that my desires to protect and reach students are projections of my fears of the vulnerability of my own interiority. Therefore, during crisis, the idea of education as a dream (e.g., the ability to protect and reach students) is itself put into crisis. Dreaming offers an avenue toward examining the collapse of the dream of education and the possibilities for attending to the conflict that ensues from it. In this article, I will pursue how teachers can move toward an ethic of care in a time of crisis.

\section{The impossibility of education}

While Freud was not prolific on the topic of education, he did name it as an impossible profession, alongside psychoanalysis. Taubman (2012, p. 2) elaborates on Freud's early formulations: The eruptions of the unconscious can "disrupt the closure, transparency, and causal narratives that education and psychoanalysis often pursue". While we may seek a Bildungsroman of education or analysis, it eludes us, and we are left with the uncontainable, uncontrollable, and ambivalent. We maintain the idealized dream of education through disavowal, or as Taubman (2012, p. 25) names it, "what education knows, but doesn't want to know it knows". For example, "[education] knows that the idiosyncratic subjectivities of student and teacher subvert any attempt at controlling outcomes or predicting success". Taubman destabilizes this idea of being able to control learning, which can become a fetish for other desires to control. Schooling not only represents its own material realities but becomes symbolic of a whole societal endeavor toward an idea of progress. 
This "profoundly unsettling" (p. 25) knowledge may prove to be a crisis in and of itself for those becoming teachers or for teachers operating under the guise of education as the greatest hope for societal and personal impact. We place so much in the basket of education that it dangerously and inevitably tips toward the precarious edge of the unconscious. On its wobbly edge, our illusions of control, dominance, and coherence teeter toward spillage, as the eruptions of the unconscious reveal them to be a mirage. As the basket tips further, in the wake of crisis we fear the splattering out of what we know but don't want to know we know-that education is, in fact, an impossible dream.

Felman (1982, p. 22) teases us with the impossibility of education: "If teaching is impossible... what are we teachers doing?". It is by "giving us unprecedented insight into the impossibility of teaching", she contends, "that psychoanalysis has opened up unprecedented teaching possibilities, renewing both the questions and the practice of education" (p. 22). Bion (2013) argues that we interpret so that we can discover the limits of what we know. Therefore, in understanding through psychoanalysis the impossibility of education, we open up the possibility of learning about learning and its vicissitudes.

\section{The crisis of violence and the impossibility of protection}

During the winter of 2019, a series of antisemitic hate crimes in the New York metropolitan area materialized into physical violence against Jews, mostly ultra-Orthodox Jews, and the threat of violence against Jews more generally. These included stabbings in homes and on the street, along with a deadly shooting in a kosher supermarket (Kilgannon 2019). These events coincided with an increase in physical fighting between students at the school in which I was working. During this time, I kept a dream journal and documented the following dream:

I had a really scary dream that people were going around to Shabbat dinners on a college campus and killing people by injecting them with things that looked like pens. The setting looked like aspects of a liberal arts college, but it was a bigger, state university campus. There was something familiar yet anonymous about it. One Shabbat dinner took place on or near a balcony with a beautiful but dark forest vista. The more interior we got, though, the scarier it became. The interiors were small, enclosed, windowless rooms with dark wooden paneling. They were not visible to the outside and felt entrapping. During the dream, I would move between these spaces, as would the assassins. The head of the school was recruiting students to kill other students. And I was leading a team that was trying to stop it. I was a part of the resistance movement. The pens they were using to kill were filled with pigs' blood. They would inject the pen and it would poison the Jews. I remember being really fearful but knew that this was my duty, to be a part of the resistance. I don't remember being directly targeted myself, but I was terrified.

The crises of this dream are multiple. The school as an imagined site of safety is inverted into a site of violent persecution, invoking the specter of school violence. Students are persecuted for their religious identity and their religiosity—not only because they are Jewish, but because they practice their religion at ritual Friday night meals. And there is also my own crisis: Am I able to protect and save students? Am I myself a victim/student? What is my proximity to violence? I am located in the flux of savior and victim, one who desires to protect (to save) but also sits ambivalently in relationship to my own vulnerability. 
In the dream, I experience a crisis of interiority. In my journal, I write: "The more interior we got, though, the scarier it became". This may reflect my fear of my own unconscious-a fear of examining "the war within" myself (Britzman 1998, p. 133). As I peel back the layers of this fantasy about saving others, I begin to see its underside. Britzman and Pitt (1996, p. 122) write about "the transferential time of pedagogy, casting the time of learning backward and forward". In this collapse of the dream, time is pendulating, as I play out my own past sticky moments of not being able to protect myself from my own interiority. This fear of the internal world - its desires, memories, fantasies - animates psychoanalysis. Freud attends to these sublimations as our fears of the past precluding possibilities of the future (Phillips 2014). His positionality as an early twentieth-century Jew testifies to the precarity of the future as haunted by past persecution. For Freud and for myself, this "transferential time" is located in a specifically Jewish context, one of resisting and approximating assimilation, of proximity to both persecution and ever-expanding privilege and protection. This translates in the dream to my pendulating in an ambivalent relationship to my own vulnerability.

What do I fear I will find in the "windowless rooms" inside the "wooden paneling"? Perhaps I will find the collapse of my dreams/fantasies; perhaps I will discover that I cannot fully insulate others or myself from violence, even if the room is windowless and dark and others cannot see inside. I desire a sense of closure-an assurance that neither I nor other students will be harmed. But the only closure I have is my own closing on my interiority. The desire to be insulated and thus safe translates to others not being able to see into the windowless rooms. This does not actually save me or others but seeks to save us from the tumult of the unconscious. Thus, I became trapped in my own fantasy of protection.

My urgent impulse to protect others reflects a trend in education "to find practical solutions or the correct technique", which precludes "the opportunity to even name conflicts, let alone work them out" (Britzman and Pitt 1996, p. 123). It also reflects affects and discourses of Whiteness that the White teacher must and can save her Black and Brown students, enacting familiar scenes of White saviorism. As I play out these tropes of fixing and saving, I see their impossibility. No one is free from the poisonous pens, neither inside the windowless rooms nor outside, in front of the dark forest scenery.

I move between these spaces of openness (the forest vista) and enclosure (windowless rooms), though both are notably dark. The pendulating transferential time takes me between spaces in which I am in different relation to my feelings about the crisis. The interior dark spaces feel dangerous because they might erupt and because no one can see inside. The outside, still dark but open, feels freer but frightening since these violent scenes could transpire even as onlookers witness. The crises, again, are multiple and paradoxical: the fear of not being seen and being seen.

When I free-associate to this dream, I think of the Einsatzgruppen, a killing squad whom the Nazis ordered to round up groups of Jews and shoot them in the deeps of forests. This terrifies me, but I also disavow my proximity to it. As the granddaughter of Holocaust survivors, I am generations removed from these events, though they are close to me. This memory haunts me like a dream I have once had and seeps into my consciousness as I move in and out of the dark spaces of schooling. The pens-instruments of learning and, in the dream, instruments of death—are filled with pigs' notoriously unkosher blood. In this gruesome twist, Jewish students are being killed by the very thing that they are not supposed to consume concealed inside the very tool that is supposed to be an instrument of learning. Bad objects and good objects are mixed and muddled, along with education as a dream. What we thought would save us is killing us. The dream of education, exposed for its madness, in my dream. 
The dream surfaces the paradoxical feelings of agency and disempowerment. I so urgently and eagerly want to protect the vulnerable students, but I myself feel fearful and thus grasp at power. The dream and my attempt to interpret it hinge on a desire for knowledge - a desire to be legible to myself and to my students: knowability. Schooling itself exists at the crux of this desire for knowledge; however, knowledge proves slippery and elusive as an object. Felman (1982, p. 33) argues that knowledge "is not a substance but a structural dynamic". Knowledge, therefore, is a relationship formed largely through utterances of the unconscious which "say more than they know" (p. 33). We-teacher and student-are thus mutually constitutive of each other and need each other in order to come to know. Psychoanalysis might offer that there is no learning (or dreaming) outside of relating.

This structural dynamic is constituted by the teacher inhabiting the position of "the subject presumed to know" (p. 34), who in the case of the dream becomes the subject presumed to know how to protect. This is not only a projection of the student but an internalized projection of the teacher. Felman argues that getting rid of an assumption that one (a teacher, an analyst) can have absolute knowledge, or mastery, does not actually get rid of the idea of this. And the idea, while revealed to be a "mirage" —or false idealization-sustains its power as a signifier around which dialogic encounters take place. This is where the mechanism of transference emerges, as there is "a subject presumed to know" onto which "the compulsive unconscious reproduction of an archaic emotional pattern" (p. 35) takes shape. Therefore, the student or patient harbors some kind of desire toward the teacher or analyst as a figure with knowledge and authority, and through this emotional engagement, plays out relationships to previous authority figures (e.g., primary caregivers) and to the idea of authority itself. The teacher, too, plays out their own crisis of being seen as the authority as they return to their own childhood and relationship to knowledge in becoming a teacher.

The transference is not a unidirectional force but a web of relationality that positions students and teachers as desiring something of the other and imagining something of the self. Britzman and Pitt (1996, p. 121) explain what happens when this dynamic is disrupted: "The stakes are most obvious when the teacher's self becomes destabilized in her encounter with others who refuse the role of self-reflecting mirror to the teacher's desire". For instance, what happens when I do not want students to fight, but they do? Britzman and Pitt argue that the pedagogue attempts to "control the stabilization", demonstrating how "transference refers to the repetition of familiar strategies of selfmastery that work to maintain the illusion of the self as a coherent and cohesive entity in charge of itself" (p. 121). So I attempt to save the students/Jews because that will return me to my projected location as the subject presumed to protect, and it will return the students to where I want them to be-in their role as good subjects who do not enact violence against each other. This is a desire to elude conflict through reiterations of the transferential subject positions. This is also reflective of my own desire to erase my vulnerability as a student in the dream who seeks to inhabit the teacher subject position of protector. What then happens when the subject positions are collapsed in my dream, wherein I am both student and teacher? I try to save others but can't save myself from my own interiority. I then begin to examine my own desires as pedagogue: What does this fantasy of protection return me to and keep me from? Instead, if I imagine myself and my students (and myself as a student) as vulnerable, a more relational learning can ensue.

Pitt and Britzman's (2003, p. 761) "transferential qualities of learning” work against a rational or linear understanding of learning - the assumption that, given the right 
conditions, knowledge will be transferred and accumulated. This idea of linearity and progress can also be termed history. Pitt and Britzman (2003, p. 761) offer an alternative view:

The transference represents both the obstacles and promise made from emotional ties consisting of love, hate, and ambivalence toward both new and old events. Transference is the signature we make upon histories of learning, but it writes in invisible ink. If learning begins with efforts to sustain one's continuity-through familiarity-the transference represents something of one's unresolved conflicts that remain obscured until acknowledgment of the emotional experience of knowledge itself can be symbolized.

Transferential learning, therefore, surfaces these sticky attachments to learning or the "emotional experience of knowledge". Crisis destabilizes the supposed subject positions of teacher and student as giver and receiver of knowledge, and in this shaking up, we have the opportunity to symbolize "the obstacles and promise" made from the residue of "love, hate, and ambivalence toward both new and old events". The dream emerges in the middle of this shaking up, and as teacher, I learn about the limits of my capacity to protect, as well as my own desire to be protected. Both are reverberations of the past family trauma of the Holocaust, which I did not directly experience but have inherited. I was not able to save my family from the violence of the Holocaust; nevertheless, I exist in a liminal space between vulnerability and protection when I imagine my own present-day proximity and distance to antisemitism. This positionality bleeds into my subjectivity as a teacher caught up in the middle of school violence-there is a desire to protect others without being fully able to, along with a desire to protect myself but an inability to admit this interiority to my students. I am stuck in my own windowless room.

The impossibility of the "dream of education" is played out in my own dream as my desire to save my students. Realizing that I am unable to prevent violence erupting between students at school, I seek to sew this rupture in a heroic attempt to save students. I become "the resistance" against the system that makes their bodies vulnerable to each other and to myself. My fear is thus located not only in my inability to save students but also in my inability to save myself. The resistance in the dream (as a kind of politicized movement) is also mirrored in my resistance to the countertransference. Britzman (1998, p. 41) explains this resistance as the disavowal "that the analysand affects the analyst's own feelings". My acts of resistance in the dream, therefore, can also be read as my own attempt to disavow the impact of the school violence and antisemitism on my psyche. It is too painful to acknowledge that it hurts me, that it surfaces past trauma and feelings of ambivalence around proximity to and distance from violence. It is too painful or uncontainable to acknowledge that I cannot really protect students. It is too painful to acknowledge that I cannot really protect myself - though perhaps what I fear most and need to shield myself against most are my own feelings of pain.

My fantasy of resistance, therefore, projects my own desire for control and power just as I lose it as a possible victim of antisemitism or of the impossibility of education. While the push to "sustain one's continuity" (Pitt and Britzman 2003, p. 761) through learning often prevails, it breaks down in crisis. Here the crisis of violence reveals the "invisible ink" (p. 761) of transferential learning. Through my dream, I come to realize the crisis of being named "the subject presumed to know" (Felman 1982, p. 34) when I myself do not knowwhen I, in fact, feel more proximate to victim than to protector. The dream confuses and reifies these imagined roles of schooling as students are pitted against each other through the tutelage of the school leader, while reified as the teacher (myself) tries to save the students. However, I wonder, was I a teacher in my dream or a student? My own subjectivity 
is confused, and so I float somewhere between these subject positions, oscillating in crisis between receiver and giver of knowledge. There is no resolution, but there is a movement toward the simultaneity of vulnerability and resistance, not reified as teacher/student subject positions but as ways of learning in crisis.

\section{The crisis of remoteness and the impossibility of reaching students}

The pandemic has cast its pervasive shadow over life as we knew it. It has brought with it the crisis of illness and a global threat to health but also a crisis of remoteness or relationality. Due to measures of social distancing, regular in-person schooling has been canceled and many classes are online. We are no longer bodies together in shared space as we learn and live but remotely operating and making attempts at learning, connection, survival and normalcy. Early in this crisis, days after we learned that classes would move online, I had the following dream:

I was walking down a busy city street in Harlem. People were going to work and people were going to school. The streets were kind of bustling, even though in my head I thought, but aren't we supposed to be quarantined? I longingly scanned the faces of the young people passing by on the street, searching for students-hoping that I might recognize one of them as a current or former student. There were fruit vendors on the street. Life appeared to have a semblance of normality, but I couldn't stop thinking, shouldn't we all be inside, or is this real? I think I see someone I recognize, but it's impossible to tell if it's him. I stare at him as I walk past and can't determine if it's really him. The dream makes me think it's his doppelgänger. For some reason, I think all my students would be in Brooklyn, so it couldn't be him.

Within the crisis of Covid-19 emerges the crisis of "reaching" students. As a teacher and as a person, I desire connection with my students. In the dream, I look with desperation, longingly, for someone I recognize so that I can perform the transferential relationship of teacher to student, wherein I comfort the student. This structural dynamic reveals a new story about old stories, in that I am looking to resuscitate the old story about teachers "reaching" (read: transforming) students from hardship to a place of comfort. Britzman and Pitt (1996, p. 117) explain that "unexpectedly, new experiences conjure old ones". In the dream, I am looking to find a former student in a new face. I wonder what it is about this current crisis that conjures old ones? The dream surfaces the unstable and shifting ground of being a new teacher, Is what I am doing actually working? Am I in fact having an impact on students and their learning?

I imagine the student in the dream whom I am trying to comfort and bring back to normalcy is perhaps myself. The impossibility of this old story (that we cannot actually control or predetermine what our impact will be on students or what their impact will be on us) is retold in anxious attempts to capture a sense of control. This deep desire to bring comfort works against the psychoanalytic instinct to attend to "the war within" (Britzman 1998, p. 133) or the complexities of the interior life. The real danger in the dream is not the disease but the insurmountability of actually reaching and connecting with a student-a casualty of remote learning. It is a new edition of an old conflict around the impossibilities of education (Freud 1968).

The specter of online learning haunts teachers who desire to really connect with students. What, after all, does it mean to learn when we are disembodied images on a screen or, even more remotely, contained as the instructions to an assignment? What happens to 
transference when teachers and students turn into symbols of themselves as they move further and further into the ether of the internet? This narrative itself has perhaps been coopted by a dystopian sentiment, grounded in the apocalyptic feelings of a socially distancing world. Stated differently, my interpretation of the dream is a projection of my fear of loss of control over a world (or a classroom) that I thought I knew (or thought I controlled). What the impossibility of education reveals here is that I perhaps never fully knew (or controlled) the classroom, as the unconscious prevented any attempt at closure (Taubman 2012). And so, the unreachability of students in the current crisis of remote learning is only a magnification of the unreachability of students always, in that we cannot control our impact on other human beings. Therefore as I stare at this student in my dream, I seek to encapsulate him in his knowability as the student I once taught, but this eludes me. My own transferential projection onto him, as the subject presumed to learn, destabilizes my own positionality as the subject presumed to know/teach/reach. This almost encounter (in that I never actually know if it is him or speak with him) destabilizes the structural dynamics embedded in the dream of education. I now experience the loss of the possibility of reaching students threefold: in the theoretical, in the real, and in the dream.

However, there is something quite obvious that we are grieving in the loss of learning together as bodies in a shared space-the loss of in-person connection. This is perhaps what I was incessantly attempting to grasp by recognizing the student in my dream. I am not able to resolve my puzzle here, as the student does not reveal himself to be himself or even to be the doppelgänger. He is unlocatable. I am therefore left with an estrangement from him, as he and I both continue to walk on the street in opposite directions. I seek to restore normalcy by resurrecting the structural dynamic of teacher and student, within which I fantasize that I know what it means to help, to comfort, to reach.

Freud and Strachey (1919) explain the doppelgänger as a motif of the uncanny. The doppelgänger becomes a splitting of the self, relegating the indigestible parts of the self to a second, sinister other that is a mirror of the self. The doppelgänger of my student therefore may symbolize the splitting that I undergo as a teacher reconciling with my own loss of control, as I fear I am not able to reach my students anymore.

There is also a duplicitousness to the dreamlike/real-like quality of the dream (and dreaming more generally). I write, "Life appeared to have a semblance of normality, but I couldn't stop thinking, shouldn't we all be inside, or is this real?". And in the first dream, the environment is familiar yet anonymous. I wonder, am I being deceived by my dreamis this fiction or reality? The dream surfaces the crisis of the pandemic, which destabilizes our relationship to reality. Is this life as normal, or are we dreaming? This motif of duplicity resonates with a sense of online learning as a deceptive mode of seeing each other, as we do not really see each other. We engage with images, ideas, and symbols of each other online but must disavow that we are not in-person together. Once we interrogate this disavowal, we are unreachable to each other and the learning is eluded. In the dream, I so badly wanted to talk to this student but could not because he was not my student. Nonetheless, I remain attached to the idea of him as my student, to the structural dynamic of transferential love, because I seek to uphold my own fantasy of power or control to transform others through learning.

While the streets in my dream are "bustling", I experience these events alone. I somehow am not able to access real human connection, a reflection of the crisis of remote learning but also of being trapped inside my own interiority. This stuckness is conveyed as I walk down the street in Harlem but do not engage with the street vendor. The fruit is there-an offering of sustenance, a palliative to get through the uncertainty and unknowingness of the crisis, but I do not buy fruit or engage with the vendor. It is there rather as 
a part of the scenery - a reference to vitality and livelihood, perhaps of a an earlier time. Now, it seemingly exists as a symbol for nurture and sustenance. The fruit may serve as a reminder to take care. How then do I pivot myself to tend to my own bustling interior life, ripe with fear and desire, and also to my newly evolving remote relationships with students? Now that I have looked beneath the veil of the dream of education, what next?

\section{Toward an ethic of care in crisis}

My interpretations of my own teacher dreams collapse the fantasy of the dream of education and reveal its underside. As I outline the transferential ties of teaching I note the ways in which my anxious attempts to protect and reach students are projections of my fears of my own vulnerability/interiority. What next?

Though the dream of education is an impossibility always, and particularly in the time of crisis, this does not mean that education should not intervene. I seek to work through my own conflict and my conflict with students. What has it meant for us to not be together? What has been hard about this? When we work through, together, what we have learned in and during this crisis, it may move us beyond the façade of the dream of education.

Dreaming in crisis invites us to interrogate learning experiences as a means of mining for and moving through our own conflicts. While education cannot be a cure to violence or illness, Britzman (1998, p. 129) argues that "it can be a cure only in the psychoanalytic sense: in creating new conditions for the capacity to love, to work, and to learn without invoking more harm and suffering". Therefore, dreaming about education in crisis allows us to peel back our projections, to work through the underside and emerge with new possibilities for connection and learning. In other words, "The work of education must be a working through of education" (Britzman 1998, p. 19). My own attempts at dream analysis seek to be a working through of education: interminable, unresolved, and caught up in its own resistance, as I begin to imagine ways of learning from and beyond crisis.

\section{References}

Bion, W. R. (2013). Attention and interpretation: A scientific approach to insight in psychoanalysis and groups. London: Routledge.

Blechner, M. J. (2018). Mindbrain and dreams: An exploration of dreaming, thinking, and artistic creation. New York, NY: Taylor \& Francis Group.

Bowles, S., \& Gintis, H. (2011). Schooling in capitalist America: Educational reform and the contradictions of economic life. Chicago, IL: Haymarket Books.

Britzman, D. P. (1998). Lost subjects, contested objects: Toward a psychoanalytic inquiry of learning. Albany, NY: State University of New York Press.

Britzman, D. P., \& Pitt, A. J. (1996). Pedagogy and transference: Casting the past of learning into the presence of teaching. Theory into practice, 35(2), 117-123.

Felman, S. (1982). Psychoanalysis and education: Teaching terminable and interminable. Yale French Studies, 63, 21-44.

Freud, S. (1968). Introductory lectures on psychoanalysis (Part III). In Standard edition, vol. 16 (J. Strachey, Trans.). London: Hogarth Press.

Freud, S., \& Brill, A. A. (1913). The interpretation of dreams. New York, NY: MacMillan.

Freud, S., \& Strachey, J. (1919). The "uncanny". (First published in Imago, Bd. V., 1919; reprinted in Sammlung, Fünfte Folge, Alix Strachey, Trans.). https://web.mit.edu/allanmc/www/freud1.pdf.

Kilgannon, C. (2019, December 31). Anti-semitic attacks put New York on edge. The New York Times. https ://www.nytimes.com/2019/12/31/nyregion/nyc-anti-semitic-attacks.html. 
Phillips, A. (2014). Becoming Freud: The making of a psychoanalyst. New Haven, CT: Yale University Press.

Pitt, A., \& Britzman, D. (2003). Speculations on qualities of difficult knowledge in teaching and learning: An experiment in psychoanalytic research. Qualitative Studies in Education, 16(6), 755-776.

Taubman, P. M. (2012). Disavowed knowledge: Psychoanalysis, education, and teaching. New York, NY: Routledge.

Publisher's Note Springer Nature remains neutral with regard to jurisdictional claims in published maps and institutional affiliations.

Maddie Neufeld is a doctoral student and instructor in the Department of Curriculum \& Teaching at Teachers College, Columbia University. She received her MA in Secondary Inclusive Education from Teachers College. Her research interests include affect theory, critical whiteness studies, dis/ability studies, and psychoanalysis in education. Maddie has also spent time in the classroom as a secondary special education teacher in New York City public schools. 